\title{
Dermatological Manifestations in Diabetes Mellitus at NGMCTH Kohalpur
}

\author{
Pandey $\mathrm{S}^{1}$, Mishra $\mathrm{P}^{2}$, Sharma $\mathrm{N}^{3}, \mathrm{BK} \mathrm{S}^{4}$
}

\begin{abstract}
Background: Skin is the largest and most visible organ in the body. It undoubtedly determines to a great extent our appearance and plays a major role in socio-sexual communication. More than one third of diabetic patients have some type of dermatologic manifestations during the course of their chronic disease ${ }^{1}$. The association of certain skin diseases with diabetes mellitus has been fairly well recognized with an incidence rate ranging from $11.4 \%{ }^{2}$ to $66 \%{ }^{3}$. At least $30 \%$ of patients with diabetes mellitus have some type of cutaneous involvement during the course of their chronic disease ${ }^{4}$. Skin sugar levels run parallel to the blood sugar levels ${ }^{5}$. Skin changes generally appear subsequent to the development of DM but may be the first presenting sign or even precede the diagnosis by many years. Among the many skin manifestations in DM, none is pathognomonic of this disease ${ }^{6}$. Cutaneous findings in DM can be classified into four categories: (1) skin disease with strong association and others with less distinct association with DM, (2) cutaneous infections, (3) dermatological disorders related to diabetic complications, and (4) skin conditions related to diabetes treatment ${ }^{7}$. Objectives: This study was undertaken to find out the pattern of Dermatological manifestations in Diabetes patients attending Nepalgunj Medical College Teaching Hospital, Kohalpur. Method and material: This is a hospital- based descriptive study conducted in the Department of Dermatology, Venereology and Leprology of Nepalgunj Medical College Teaching Hospital, Kohalpur between September 2013 to August 2014. A total of 100 patients were included in the study. History and clinical examinations were performed and the data were recorded and analyzed. Results: The age of the patients ranged from 20 years to 85 years with the mean age of $51.7+12.13$ years. The most common age groups were $46-55$ years (36\%) followed by $56-65$ years $(24.7 \%)$ and $36-45$ years $(17.3 \%), 66-75$ years $(9.3 \%), 76-85$ years $(12.7 \%)$. Among the 100 patients of diabetes mellitus, there were $44(44 \%)$ males and $56(56 \%)$ females. Among the cutaneous disorders commonly associated with diabetes, infections were the most prevalent. 59(59\%) out of 100 patients had skin infections. Conclusions: Patients with Diabetes can present with array of cutaneous disorders. Cutaneous infections formed the largest group of dermatoses in this study. Increased incidence of cutaneous infections mainly fungal and bacterial was noticed in majority diabetics emphasizing the need for more aggressive management of diabetes mellitus. Among infective dermatoses, fungal infections were the most common, with Candidal infections being more common than dermatophytosis.
\end{abstract}

Key words: Dermatoses, diabetes mellitus

\section{INTRODUCTION}

Diabetes is one of the first diseases described and Mention of the symptoms of diabetes has been found since ancient times. Egyptian physician Hesy-Ra of the $3^{\text {rd }}$ Dynasty makes the first known mention of diabetes- found on the Ebers Papyrus- and lists remedies to combat the "passing of too much urine". The term diabetes was coined by Aretaeus of Cappadocia, a Greek physician who in $250 \mathrm{BC}$ gave the first complete medical description of diabetes, which he linked to "the melting down of flesh and limbs into urine" ${ }^{\prime 8}$. The term "mellitus" or "from
1. Dr. Sumit Pandey
2. Dr. Pradip Mishra
3. Dr. Nirmala Sharma
4. Dr. Shyam B.K.

Address for correspondence:

Dr. Sumit Pandey

Department of Dermatology

Nepalgunj Medical College Teaching Hospital

Kohalpur, Banke, Nepal

Email: sumitpandey207@yahoo.com honey" was added by the Britain John Rolle in the late 1700 s to separate the condition from diabetes insipidus which is also associated with frequent urination ${ }^{9}$. The term diabetes mellitus describes a metabolic disorder of multiple etiologies characterized by chronic hyperglycaemia with disturbances of carbohydrate, fat and protein metabolism resulting from defects in insulin secretion, insulin action, or both.

The effects of diabetes mellitus include long-term damage, dysfunction and failure of various organs. These range from autoimmune destruction of the $\beta$ cells of the pancreas with consequent insulin deficiency to abnormalities that result in resistance to insulin action ${ }^{10,11}$. WHO estimated a prevalence of 511,000 cases of diabetes in Nepal for 2010 and this figure is expected to more than double to over 1.07 million by 2030 with a mean annual increment of 28,000 cases $^{11}$.

Diabetes affects every organ system and the skin is no exception. ${ }^{12}$ Cutaneous infections are more common in Type 2 diabetes, whereas autoimmune-related lesions are more common in Type $1^{13}$. The association of certain skin diseases 
with diabetes mellitus has been fairly well recognized with an incidence rate ranging from $11.4 \%$ to $66 \% \%^{3,8}$. Multiple factors play a role in the manifestations of cutaneous signs of diabetes mellitus. Abnormalities in the metabolism of carbohydrates, alteration of metabolic pathways, vascular involvement in the form of atherosclerosis, microangiopathy and neuronal involvement in the form of sensory, motor and autonomic neuropathies and impaired host mechanisms, all play a role.

\section{METHODS \& MATERIAL}

This is a Hospital based retrospective study conducted in the Department of Dermatology and Venereology, Nepalgunj Medical College Teaching Hospital Kohalpur, between September 2013 to August 2014. Diabetic patients attending the diabetic clinic of NGMCTH, Kohalpur Medicine OPD and Dermatology OPD with skin manifestations were included. A total of 100 patients were included in the study.

$44 \%$ were male and $56 \%$ females. Informed consent was obtained. A detailed history was elicited with particular reference to cutaneous complaints and including details regarding duration, history of evolution, progression and treatment modalities. Clinical examination included general physical examination followed by a meticulous examination of the lesion done to make a diagnosis and investigations such as $10 \% \mathrm{KOH}$ smear where required. Control of Diabetes was assessed by available HbA1c levels, FBS, PPBS levels.

\section{RESULTS}

A total of 100 patients who were diagnosed as diabetes and had skin problem were included in the study and were evaluated for the type of skin manifestations. The most common age group of diabetic patients with skin manifestations were in $4^{\text {th }}$ to $5^{\text {th }}$ decades (36\%).

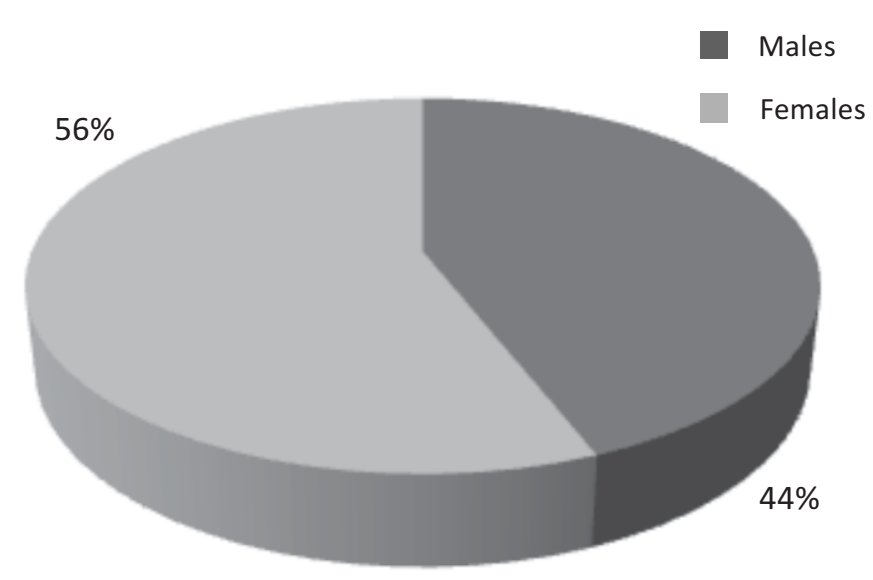

Figure 1: Gender distrbution
Among the cutaneous disorders commonly associated with diabetes, infections were the most prevalent, 59 out of 100 patients had skin infections and 41 had non-infective dermatosis. Of the total $59 \%$ cases with infections, fungal infections were the commonest and were seen in 36(61.01\%) patients, followed by bacterial infections in $18(30.5 \%)$ and viral infections 4(6.77\%) and parasitic infestation 1(1.69\%).

\begin{tabular}{|c|c|c|}
\hline & Frequency & (\%) \\
\hline Fungal & 36 & 61.01 \\
\hline Bacterial & 18 & 30.5 \\
\hline Parasitic & 1 & 1.69 \\
\hline Viral & 4 & 6.77 \\
\hline
\end{tabular}

Table I: Pattern of infective dermatoses in diabetic patients

\begin{tabular}{|l|c|c|}
\hline Candidal Infection & Frequency & (\%) \\
\hline Intertrigo & 15 & 41.66 \\
\hline Vulvovaginal Candidiasis & 2 & 5.5 \\
\hline Candidal Balanophosthitis & 6 & 16.66 \\
\hline Dermatophytic infections & \multicolumn{2}{|l|}{} \\
\hline Onychomycosis & 2 & 5.55 \\
\hline Tinea pedis & 1 & 2.77 \\
\hline Tinea corporis & 4 & 11.11 \\
\hline Tinea incognito & 3 & 8.33 \\
\hline Tinea cruris & 3 & 8.33 \\
\hline
\end{tabular}

Table II: Pattern of fungal infection in diabetic patients

\begin{tabular}{|c|c|c|}
\hline Bacterial Infections & Frequency & (\%) \\
\hline Folliculitis & 4 & 22.22 \\
\hline Furunculosis & 8 & 44.44 \\
\hline Abscess & 4 & 22.22 \\
\hline Carbuncle & 1 & 5.55 \\
\hline Cellulitis & 1 & 5.55 \\
\hline
\end{tabular}

Table III: Pattern of bacterial Infection in diabetic patient

Pattern of Non infective dermatoses in diabetic patients

Various non-infective dermatoses were noted among the 41 diabetic patients. Few patients had more than one manifestation. The most common findings were pruritis (localized or generalized without any skin lesions) and xerosis seen in $7(17.07 \%)$ patients each. Prurigos, mainly on limbs were seen in 4(9.75) patients. Eczema of various forms including seborrhoeic dermatitis and hand eczema was seen in another 2(4.87\%) cases. Dermatoses strongly associated with DM including, acanthosis nigricans, bullosa diabeticorum, granuloma annulare, diabetic dermopathy, necrobiosis 


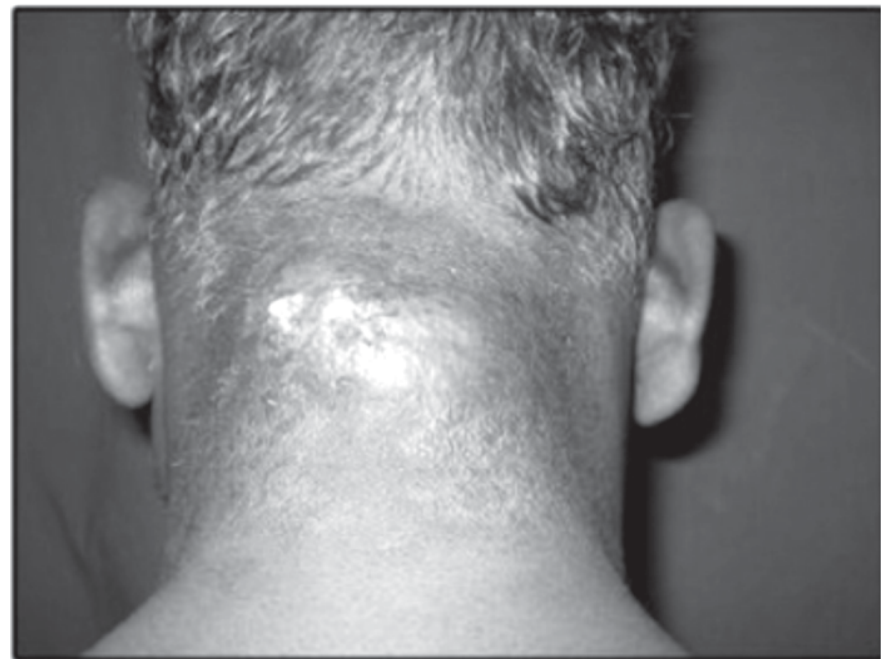

Figure 2: Carbuncle at the back of the neck

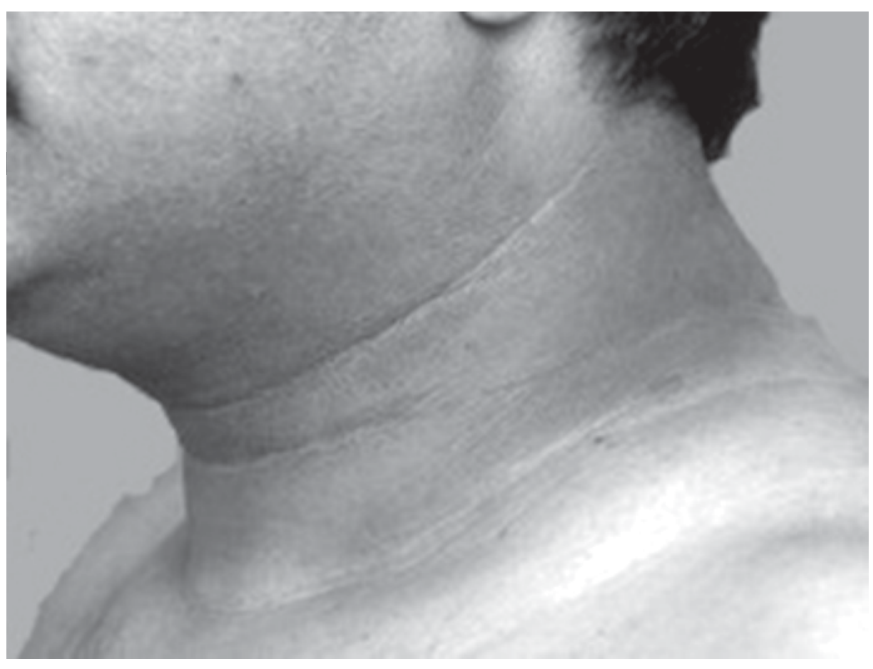

Figure 3: Acanthosis nigricans

lipoidica were seen in 5(12.9\%), 3(7.31\%), 1(2.43\%), 1(2.43\%), and $1(2.43 \%)$ patients respectively. Few patients had other skin conditions less associated with diabetes such as vitiligo in $3(7.31 \%)$ patients, acrochordi in $2(4.87 \%)$ patients and pigmented purpuric dermatosis in 1 (2.43\%) patient and others $4(9.75 \%)$.

\section{DISCUSSION}

Diabetes mellitus is a disease which commonly involves the skin. Cutaneous manifestations of diabetes mellitus generally appear subsequent to the development of the disease, but may be the first presenting signs, and in some cases they may precede the primary disease manifestation by many years ${ }^{14}$. Some diabetes-associated skin conditions are a direct result of the metabolic changes such as hyperglycemia and hyperlipidemia, in addition to other contributing factors, which include progressive damage to the vascular, neurological or immune system. Minor skin manifestations are ignored by the patients and they seek help of the doctor only if there is any major problem which does not heal with ordinary medications.In this study, the most common age group of diabetic patients with cutaneous manifestations is between 46-55 years, whereas in a study by Mashkoor ahmed et $\mathrm{al}^{15}$ of 51- 60 years. Bhat et a ${ }^{16}$ and Mahajan et al. ${ }^{17}$ in their studies on diabetes mellitus, documented the most common age group of the study population, with or without dermatoses, to be of $41-50$ years in 33.3 and $33 \%$ of the patients, respectively.

The female predominance was seen in our study similar to the findings of Mashkoor ahmed et a ${ }^{15}$ Mahajan et $a{ }^{17}$ and Romano et $\mathrm{al}^{18}$. A study by Ahmed et $\mathrm{al}^{15}$ also indicated that skin diseases were more prevalent in women than in men. Binkley ${ }^{19}$ and Danowsky et $\mathrm{al}^{20}$ whereas observed a higher incidence of cutaneous diseases among male diabetics. Also a study from Sargodha, Pakistan found skin disorders more in men than women $^{21}$.

In this study, cutaneous infections were the most common cutaneous manifestations seen in 59\% of the cases, Similar to the observation of our study, Nigam and Pande ${ }^{22}$ and Ahmed et $\mathrm{al}^{15}$ found cutaneous infections to be the most common dermatoses in their studies. The increased incidence of cutaneous infections in diabetes may be related to abnormal microcirculation, hypohidrosis, peripheral vascular disease, diabetic neuropathy, decreased phagocytosis, impaired leukocyte adherence, and delayed chemotaxis ${ }^{23,24}$. In this study, cutaneous fungal infections were the most common and were seen in $61.01 \%(36)$ of the cases, followed by bacterial infections in $30.5 \%(18)$ and viral $6.77 \%(4)$ and parasitic $1.69 \%(1)$. Dependra et $a^{25}$ also showed cutaneous fungal infections to be the most common infection among diabetics and were seen in $30.4 \%(68)$ of the cases, followed by bacterial infections in 16.5\%(37) and viral infections in 1 case.

Among the non infective dermatosis Pruritus and xerosis were the second most common manifestation, and were seen in $17.07 \%$ patients. Generalized pruritus is not specifically associated with diabetes mellitus, although pruritus vulvae and balanitis may be the presenting symptoms of diabetes ${ }^{24}$. Itching in elderly diabetics could be a manifestation of xerosis. Pruritus was also the second most common finding in Mahajan et al's ${ }^{17}$ study. Rao and $\mathrm{Pai}^{7}$ also found that pruritus was the main presenting symptom and was noted in $60.23 \%$ patients in their series. Xerosis in diabetics may be due to the normal xerotic process of the elderly or as a result of dehydration due to autonomic nervous system involved by the disease process ${ }^{26}$.

\section{CONCLUSION}

Patients with Diabetes can present with array of cutaneous disorders. Cutaneous infections formed the largest group of dermatoses in this study. Increased incidence of cutaneous 
infections mainly fungal and bacterial was noticed in majority of the uncontrolled diabetics emphasizing the need for more aggressive management of diabetes mellitus. Among infective dermatoses, fungal infections were the most common, with Candidal infections being more common than dermatophytosis.

In bacterial we had folliculitis forming the major group. Other commonly seen dermatoses were pruritus without any skin lesions, xerosis, prurigo, achrochordon, acanthosis nigricans, granuloma annulare, seborrhoic keratosis. The cutaneous manifestations of diabetes mellitus are due to multiple factors including abnormal carbohydrate metabolism, other altered metabolic pathways, microangiopathy, atherosclerosis, neuron degeneration and impaired host defense mechanisms. The manifestations should be actively sought in all diabetic patients, as early diagnosis and management can reduce morbidity.

\section{REFERENCES}

1. Greenwood AM. A study of skin in 500 diabetics. JAMA 1927; 89: 774-779.

2. American Diabetes Association: Diagnosis and Classification of Diabetes Mellitus. Diabetes Care Jan 2012; 35: S11-S63.

3. Chhabra SAN. Cutaneous manifestations in diabetes mellitus. Thesis submitted to Delhi University in 1978.

4. Giligor RS, Lazarus G S. Skin manifestations of diabetes mellitus. In, Diabetes Mellitus, eds Rifkin H, Raskin P, Brady co, Louana 1981, 313. 321.

5. Urbach E. Skin diabetes (hyperglycodermia) without hyperglycemia. JAMA 1945; 129:433.

6. Levy L., Zeichner JA. Dermatologic manifestation of diabetes. J Diabetes. 2012 Mar; 4(1):68-76.

7. Rao GS, Pai GS. Cutaneous manifestation of diabetes mellitus. Indian J Dermatol Venereol Leprol.1997; 63:232-4.

8. Garrison F. Historical Aspects of Diabetes and Insulin. Bull NY Acad of Med 1925; 1(4):127-33.

9. Leonid Poretsky, (2009). Principles of diabetes mellitus ( $\left.2^{\text {nd }} E d.\right)$. New York: Springer. p. 3. ISBN 978-0-387-09840-1.

10. American Diabetes Association: Diagnosis and Classification of Diabetes Mellitus. Diabetes Care Jan 2012; 35: S11-S63.

11. Shaw JE, Sicree RA, Zimmet PZ. Global estimates of the prevalence of diabetes for 2010 and 2030. Diabetes research and clinical practice (2010); 87:4-14.

12. Levy L, Zeichner JA. Dermatologic manifestation of diabetes. J Diabetes. 2012 Mar; 4(1):68-76.

13. Hattem SV, Thio HB. Skin manifestations of diabetes. Cleveland Clinic Journal of Medicine. November 2008; 75(11): 772-787.

14. Pavlović MD, Milenković T, Dinić $M$, Misović $M$, Daković $D$, Todorović $S$, et al. The prevalence of cutaneous manifestations in young patients with type 1 diabetes. Diabetes Care. 2007; 30:1964-7.

15. Mashkoor Ahmed Wani, Iffat Hassan, Mohd Hayat Bhat, and Qazi Masood Ahmed, MD Cutaneous Manifestations of Diabetes mellitus: A Hospital Based Study in Kashmir, India, Egyptian Dermatology Online Journal 5 (2):5.

16. Bhat YJ, Gupta V, Kudyar RP. Cutaneous manifestations of diabetes mellitus. Int J Diab Dev Ctries.2006; 26:152-5.
17. Mahajan S, Karanne RV, Sharma SK. Cutaneous manifestation of diabetes mellitus. Indian J Dermatol Venereol Leprol. 2003; 69:105-8.

18. Romano G, Moretti G, Di Benedetto A, Giotre C, Di Cesare E, Russo $G$ et al. Skin lesions in diabetes mellitus: prevalence and clinical correlation. Diabetes Res Clin Pract 1998; 39: 101- 106.

19. 1965 Binkley GH. Dermopathy in diabetic syndrome, Arch Dermatol; 92:625-631.

20. Danowaski TS, Sabeh G, Sarver ME, et al. Shin spots and diabetes mellitus. Amer J Med Sci 1966; 251:570-5.

21. Mahmood T, Ul-Bari A, Agha H. Cutaneous manifestations of dibetes mellitus. J Pak Assoc Dermatol 2005; 15:227-32.

22. Nigam PK, Pande S. Pattern of dermatoses in diabetics. Indian J Dermatol Venereol Leprol 2003; 69:83-5.

23. Ferringer $T$, Miller $F$. Cutaneous manifestations of diabetes mellitus. Dermatol Clin 2002; 20:483-492.

24. Sibbald RG, Schachter RK The skin and diabetes mellitus. Int J Dermatol 1984; 23:567-584.

25. Dependra Kumar Timshina, Devinder Mohan Thappa, and Aparna Agrawal. A Clinical Study of Dermatoses in Diabetes to Establish its Markers, Indian J Dermatol. 2012 Jan-Feb; 57(1): 20-25.

26. Jelinek JE. Cutaneous manifestations of diabetes mellitus. Int J Dermatol 1994; 33:605-617. 